\title{
Heat stroke with bimodal rhabdomyolysis: a case report and review of the literature
}

\author{
Toshihiko Yoshizawa ${ }^{1}$, Kazuhiko Omori ${ }^{1}$, Ikuto Takeuchi ${ }^{1}$, Yuto Miyoshi', Hiroshi Kido ${ }^{3}$, Etsuhisa Takahashi ${ }^{3}$, \\ Kei Jitsuiki ${ }^{1}$, Kouhei Ishikawa' ${ }^{1}$, Hiromichi Ohsaka ${ }^{1}$, Manabu Sugita ${ }^{4}$ and Youichi Yanagawa ${ }^{1,2^{*}}$
}

\begin{abstract}
Background: Severe heat stroke tends to be complicated with rhabdomyolysis, especially in patients with exertional heat stroke. Rhabdomyolysis usually occurs in the acute phase of heat stroke. We herein report a case of heat stroke in a patient who experienced bimodal rhabdomyolysis in the acute and recovery phases.

Case presentation: A 34-year-old male patient was found lying unconscious on the road after participating in a half marathon in the spring. It was a sunny day with a maximum temperature of $24.2{ }^{\circ} \mathrm{C}$. His medical and family history was unremarkable. Upon arrival, his Glasgow Coma Scale score was 10. However, the patient's marked restlessness and confusion returned. A sedative was administered and tracheal intubation was performed. On the second day of hospitalization, a blood analysis was compatible with a diagnosis of acute hepatic failure; thus, he received fresh frozen plasma and a platelet transfusion was performed, following plasma exchange and continuous hemodiafiltration. The patient's creatinine phosphokinesis (CPK) level increased to $8832 \mathrm{IU} / \mathrm{L}$ on the fifth day of hospitalization and then showed a tendency to transiently decrease. The patient was extubated on the eighth day of hospitalization after the improvement of his laboratory data. From the ninth day of hospitalization, gradual rehabilitation was initiated. However, he felt pain in both legs and his CPK level increased again. Despite the cessation of all drugs and rehabilitation, his CPK level increased to $105,945 \mathrm{IU} / \mathrm{L}$ on the 15th day of hospitalization. Fortunately, his CPK level decreased with a fluid infusion. The patient's rehabilitation was restarted after his CPK level fell to $<10,000 \mathrm{IU} / \mathrm{L}$. On the 31st day of hospitalization, his CK level decreased to $623 \mathrm{IU} / \mathrm{L}$ and he was discharged on foot. Later, a genetic analysis revealed that he had a thermolabile genetic phenotype of carnitine palmitoyltransferase II (CPT II).
\end{abstract}

Conclusions: Physicians should pay special attention to the stress of rehabilitation exercises, which may cause collapsed muscles that are injured by severe heat stroke to repeatedly flare up.

Keywords: Heat stroke, Rhabdomyolysis, Rehabilitation

\section{Background}

Severe heat stroke tends to be complicated with rhabdomyolysis, especially in patients with exertional heat stroke [1-4]. Rhabdomyolysis may lead to systemic effects, including the local occurrence of compartment syndrome, hyperkalemic cardiac arrest, and/or lethal disseminated intravascular coagulopathy [5-7]. Rhabdomyolysis usually occurs in the acute phase of heat stroke. We herein report a case of heat stroke in a patient who experienced bimodal rhabdomyolysis in the acute and recovery phases.

\footnotetext{
* Correspondence: yyanaga@juntendo.ac.jp

'Department of Acute Critical Care Medicine, Shizuoka Hospital, Juntendo University, Tokyo, Japan

21129 Nagaoka, Izunokuni City, Shizuoka 410-2295, Japan

Full list of author information is available at the end of the article
}

\section{Case presentation}

A 34-year-old male patient was found lying unconscious with a head injury on the road after participating in a half marathon in the spring. It was a sunny day with a maximum temperature of $24.2{ }^{\circ} \mathrm{C}$ and a humidity of $54 \%$. A physician who was transported by helicopter to check on the patient reported that his Glasgow Coma Scale score was 6 and that he presented marked restlessness. His blood pressure was $110 / 80 \mathrm{mmHg}$, his heart rate was 140 beats per minute (BPM), his respiratory rate was 40 breaths per minute (BPM), and his axillary temperature was $40.8^{\circ} \mathrm{C}$. He was transported to our hospital by a ground ambulance after the infusion of a sedative agent and the rapid infusion of cooled lactated Ringer. His medical and family history was 
unremarkable. He did not have sign of flu in a few days. Upon arrival, his Glasgow Coma Scale score was 10. His blood pressure was $116 / 86 \mathrm{mmHg}$, his heart rate was $164 \mathrm{BPM}$, his respiratory rate was $36 \mathrm{BPM}$, his $\mathrm{SpO}_{2}$ level was $95 \%$ with oxygen ( $8 \mathrm{l} / \mathrm{min}$ by mask), and his bladder temperature was $40.2{ }^{\circ} \mathrm{C}$. The physiological findings included hyperhidrosis with restless confusion. After the rapid infusion of $3500 \mathrm{ml}$ of cooled lactated Ringer and gastric lavage with iced water, his bladder temperature decreased to $38.8^{\circ} \mathrm{C}$ within $30 \mathrm{~min}$ of his arrival and the patient became calm. A chest roentgen revealed no abnormal findings, while an electrocardiogram showed sinus tachycardia without a change in the ST segments. Head CT, which was performed to determine the cause of the patient's unconsciousness, revealed no brain abnormalities; however, the patient's marked restlessness and confusion returned. To secure the patient's safety, a sedative was administered and tracheal intubation was performed. The main results of a blood analysis are shown in Table 1. On the second day of hospitalization, a blood analysis revealed the following findings: aspartate aminotransferase (AST), $144 \mathrm{IU} / \mathrm{L}$; alanine aminotransferase (ALT), $86 \mathrm{IU} / \mathrm{L}$; prothrombin activation ratio, 22\%; platelet count, $5 \times 10^{4} / \mathrm{mm}^{3}$; and ammonia level, $108 \mu \mathrm{g} / \mathrm{dl}$. These values were compatible with a diagnosis of acute hepatic failure (according to the Japanese guidelines) [8]; thus, he received fresh frozen plasma and a platelet transfusion was performed. On the third day of hospitalization, a blood analysis revealed the following findings: AST level, 14,894 IU/L; ALT level, 14,355 IU/L, prothrombin activation ratio, $43.8 \%$; and platelet count, $3.8 \times 10^{4} / \mathrm{mm}^{3}$; thus, plasma exchange was performed for 2 days, followed by continuous hemodiafiltration for 3 days. The time course of the changes in the patient's creatinine phosphokinesis (CPK) levels is shown in Fig. 1. The patient's CPK level increased to $8832 \mathrm{IU} / \mathrm{L}$ on the fifth day of hospitalization and then showed a tendency to transiently decrease. The patient was extubated on the eighth day of hospitalization, after showing the ability to respond to commands and the improvement of his laboratory data. From the ninth day of hospitalization, gradual rehabilitation was initiated; this included transferring to a wheelchair or standing at his bedside. However, he felt pain in both legs and his CPK level increased again. Despite the cessation of all drugs and rehabilitation, his CPK level increased to $105,945 \mathrm{IU} / \mathrm{L}$ on the 15th day of hospitalization. During this period, he had a low-grade fever ranging from 37.2 to $37.8{ }^{\circ} \mathrm{C}$. Fortunately, his CPK level decreased with a fluid infusion, which was administered to prevent renal failure. The patient's rehabilitation was restarted after his CPK level fell to $<10,000 \mathrm{IU} / \mathrm{L}$. On the 31st day of hospitalization, his CPK level decreased to $623 \mathrm{IU} / \mathrm{L}$ and he was discharged on foot. Later, a genetic analysis revealed that he had a thermolabile genetic phenotype of carnitine palmitoyltransferase II (CPT II).

\section{Discussion}

We herein report a case of heat stroke in a patient with bimodal rhabdomyolysis in the acute and recovery phases. We performed a PubMed search to identify any related articles using the key words "heat stroke" and "rhabdomyolysis". As a result, we found 110 articles about heat stroke with rhabdomyolysis. Among these cases, we found 17 cases involving individuals with heat

Table 1 The laboratory analysis results

\begin{tabular}{|c|c|c|c|c|c|}
\hline \multicolumn{6}{|c|}{ Arterial blood gas } \\
\hline $\mathrm{pH}$ & \multicolumn{2}{|l|}{7.374} & $\mathrm{pCO}_{2}$ & \multicolumn{2}{|l|}{$23.7 \mathrm{mmHg}$} \\
\hline $\mathrm{pO}_{2}$ & \multicolumn{2}{|l|}{$152 \mathrm{mmHg}$} & Bicarbonate & \multicolumn{2}{|l|}{$13.5 \mathrm{mmol} / \mathrm{l}$} \\
\hline \multicolumn{6}{|c|}{ Cell blood count } \\
\hline \multicolumn{2}{|c|}{ White blood count } & $8600 / \mu l$ & Hematocrit & \multirow[t]{2}{*}{$48.3 \%$} & \\
\hline \multicolumn{2}{|c|}{ Platelet } & \multicolumn{3}{|l|}{$19.2 \times 10^{4} / \mu \mathrm{l}$} & \\
\hline \multicolumn{6}{|c|}{ Serum biochemical data } \\
\hline \multicolumn{2}{|c|}{ Aspartate aminotransferase } & $46 \mathrm{IU} / \mathrm{I}$ & \multicolumn{2}{|l|}{ Alanine aminotransferase } & $35 \mathrm{U} / \mathrm{l}$ \\
\hline \multicolumn{2}{|c|}{ Lactate dehydrogenase } & $285 \mathrm{IU} / \mathrm{I}$ & \multicolumn{2}{|l|}{ Total bilirubin } & $0.6 \mathrm{mg} / \mathrm{dl}$ \\
\hline \multicolumn{2}{|c|}{ Blood urea nitrogen } & $27.3 \mathrm{mg} / \mathrm{dl}$ & \multicolumn{2}{|l|}{ Glucose } & $101 \mathrm{mg} / \mathrm{dl}$ \\
\hline \multicolumn{2}{|c|}{ Creatinine } & $2.38 \mathrm{mg} / \mathrm{dl}$ & \multicolumn{2}{|l|}{ Creatine phosphokinase } & $301 \mathrm{IU} / \mathrm{I}$ \\
\hline \multicolumn{2}{|c|}{ Sodium } & $146 \mathrm{mEq} / \mathrm{l}$ & \multicolumn{2}{|l|}{ Chloride } & $113 \mathrm{mEq} / \mathrm{l}$ \\
\hline \multicolumn{2}{|c|}{ Potassium } & $4.3 \mathrm{mEq} / \mathrm{l}$ & \multicolumn{2}{|l|}{$\mathrm{C}$ reactive protein } & $0.3 \mathrm{mg} / \mathrm{dl}$ \\
\hline \multicolumn{6}{|c|}{ Coagulation } \\
\hline \multicolumn{2}{|c|}{ Activated partial thromboplastin time $22.1 \mathrm{~s}$} & & \multicolumn{2}{|l|}{ Prothrombin time $\%$} & $74 \%$ \\
\hline \multicolumn{2}{|c|}{ Fibrinogen degradation products } & $9.3 \mu \mathrm{g} / \mathrm{mL}$ & & & \\
\hline
\end{tabular}




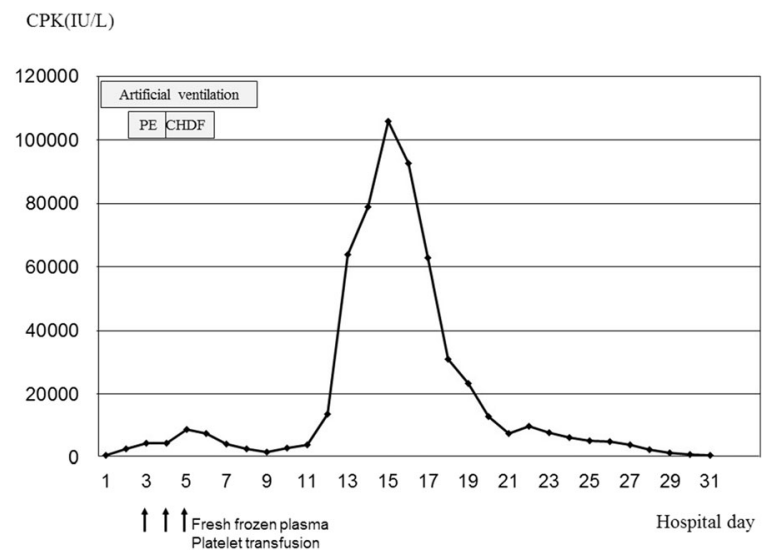

Fig. 1 The time course of the changes in the patient's creatinine phosphokinesis (CPK) data. The patient's CPK level increased to $8832 \mathrm{IU} / \mathrm{L}$ on the fifth day of hospitalization and then showed a transient tendency to decrease. From the ninth day of hospitalization and following the start of rehabilitation, the patient's CPK level increased again to reach 105,945 IU/L on the 15th day of hospitalization. PE plasma exchange, CHDF continuous hemodiafiltration

stroke complicated with rhabdomyolysis in which the time course of the CPK level was described [1, 9-24]. We summarized these cases, including the present case, in Table 2. Among them, only two reports from Japan showed bimodal rhabdomyolysis $[15,22]$. In one of these two reports, Takahashi et al. described a 16-year-old male patient who experienced convulsions 3 days after living donor liver transplantation [22]. After the convulsions on postoperative day 5 , the patient's CPK level, which had been showing a tendency to decrease, increased from 715 to $24,985 \mathrm{IU} / \mathrm{L}$. Convulsions can cause rhabdomyolysis; thus, this case report was excluded from the studies that described the natural course of bimodal rhabdomyolysis induced by heat stroke [25]. Two reports by Miura et al. described the case of 38-year-old man who experienced a life-threatening flare-up of rhabdomyolysis (CPK level of $84,612 \mathrm{IU} / \mathrm{L}$ on the third hospital day) and who was treated by plasma exchange, hemodiafiltration, steroid pulse therapy, and anticoagulant treatment [15]. His general condition was initially thought to be improving; however, his smoldering rhabdomyolysis suddenly flared up with a marked increase in his CPK level $(105,231 \mathrm{IU} / \mathrm{L}$ on the 18th day of hospitalization) when the steroid dosage was reduced and rehabilitation was initiated. Thereafter, his condition rapidly deteriorated and he eventually died, despite the provision of aggressive treatment. In addition, Fink et al. reported the case of a 16-year-old male athlete with heat stroke and rhabdomyolysis [19]. The patient survived and was discharged on day 14, but his CPK level was more than $1000 \mathrm{IU} / \mathrm{L}$ for several weeks after his discharge. Their report did not indicate whether the patient's rhabdomyolysis was bimodal. Similarly to our case, in the four Japanese reports of six patients who suffered bimodal rhabdomyolysis in the acute and recovery phases (more than 2 weeks after severe heat stroke), all of the patients could survive and start rehabilitation (Table 3) [26-29].

Table 2 A summary of the reports on heat stroke in which the time course of rhabdomyolysis was described

\begin{tabular}{|c|c|c|c|c|c|c|c|c|c|c|c|c|c|}
\hline No & Reporter & Year & Age & Sex & Trigger & 1st peak D & CPK max & $\mathrm{HD}$ & Outcome & Bimodal & 2nd peak D & CPK max & Trigger \\
\hline 1 & Wu & 2015 & 27 & Male & Exercise & 2 & 55,650 & Yes & Survival & No & & & \\
\hline 2 & Asserraji & 2014 & 35 & Male & Marathon & 5 & 91,596 & Yes & Death & No & & & \\
\hline 3 & Raj & 2013 & 11 & Male & Jog & 1 & 4326 & Yes & Survival & No & & & \\
\hline 4 & Horseman & 2013 & 22 & Male & Walking & 1 & 649,530 & Yes & Survival & No & & & \\
\hline 5 & Azzopardi & 2012 & 25 & Male & Marathon & 2 & 178,850 & No & Survival & No & & & \\
\hline 6 & Muñiz & 2012 & 15 & Male & Football & 2 & 39,954 & No & Survival & No & & & \\
\hline 7 & Trujillo & 2011 & 14 & Female & Exercise & 3 & 36,423 & Yes & Survival & No & & & \\
\hline 8 & Lin & 2011 & 11 & Female & Jogging & 2 & 21,351 & No & Survival & No & & & \\
\hline 9 & Miura & 2010 & 38 & Male & Marathon & 3 & 84,612 & No & Death & Yes & 18 & 105,231 & Reha \\
\hline 10 & Lee & 2010 & 57 & Male & Kot spring & 3 & 9565 & Yes & Death & No & & & \\
\hline 11 & Niu & 2009 & 47 & Male & Labor & 1 & 4682 & No & Survival & No & & & \\
\hline 12 & Akieda & 2008 & 75 & Male & Bath & 3 & 4299 & No & Survival & No & & & \\
\hline 13 & Fink & 2006 & 16 & Male & Football & 3 & 90,720 & No & Survival & $?$ & $>2$ wks & $>1000$ & Discharge \\
\hline 14 & Broessner & 2005 & 38 & Male & Hiking & 4 & 1024 & No & Survival & No & & & \\
\hline 15 & Wakino & 2005 & 23 & Male & Labor & 5 & 620,920 & Yes & Survival & No & & & \\
\hline 16 & Takahashi & 2005 & 16 & Male & Rugby & $?$ & $?$ & Yes & Survival & Yes & 8 & 24,985 & Convulsion \\
\hline 17 & Pechlaner & 2002 & 28 & Male & Labor & 2 & 1920 & No & Survival & No & & & \\
\hline 18 & Present & & 28 & Male & Marathon & 5 & 8832 & Yes & Survival & Yes & 22 & 9230 & Reha \\
\hline
\end{tabular}

? means not described, $D$ day, Reha rehabilitation, wks weeks, CPK creatinine phosphokinesis, HD hemodialysis, max maximum 
Table 3 The Japanese reports of bimodal rhabdomyolysis after heat stroke

\begin{tabular}{|c|c|c|c|c|c|c|c|c|c|c|c|c|c|}
\hline No & Reporter & Year & Age & Sex & Trigger & 1st peak D & CPK max & $\mathrm{HD}$ & Outcome & Bimodal & 2nd peak D & CPK max & Trigger \\
\hline 1 & Suzuki & 1996 & 23 & Male & Training & 3 & 300,762 & Yes & Survival & Yes & 20 & 14,154 & Reha \\
\hline 2 & Kajiwara & 1993 & 17 & Male & Jogging & 3 & $>15,000$ & No & Survival & Yes & 22 & 4500 & Reha \\
\hline 3 & Kuriyama & 1990 & 19 & Male & Jogging & 6 & 10,425 & No & Survival & Yes & 15 & 105,945 & Reha \\
\hline 4 & Nagao & 1985 & 21 & Male & Jogging & 6 & 5570 & No & Survival & Yes & 18 & 474 & Reha \\
\hline 5 & Nagao & 1985 & 18 & Male & Jogging & 5 & 4530 & No & Survival & Yes & 19 & 9800 & Reha \\
\hline 6 & Nagao & 1985 & 16 & Male & Kendo & 3 & 9410 & No & Death & Yes & 17 & 309,000 & Reha \\
\hline
\end{tabular}

$D$ day, $C P K$ creatinine phosphokinesis, HD hemodialysis, max maximum

Accordingly, the authors' hypothesized that during the recovery phase, the stress of rehabilitation exercises can cause collapsed muscles that are injured by heat stroke to repeatedly flared up. Drugs that are administered during intensive treatment in the acute phase may be involved in the occurrence of bimodal rhabdomyolysis. However, this possibility was considered to be unlikely in the present case because drug-induced rhabdomyolysis usually subsides when the drugs are stopped [30]. In our search of the literature, heat stroke-induced bimodal rhabdomyolysis was only described in Japanese case reports; thus, genetic differences may affect this phenomenon.

CPT II is a pivotal enzyme in mitochondrial fatty acid oxidation, which is essential for energy production during simultaneous glucose sparing and a requirement for major energy supply, such as during prolonged fasting or exercise [31]. Cases with the thermolabile genetic phenotype of CPT II have been described mainly in Japan and China. Recent studies have suggested the association of this phenotype with influenza-associated encephalopathy, encephalopathy during a high-grade fever caused by human herpesvirus-6, enterovirus 71, Echo virus, Coxsackievirus, rotavirus, respiratory syncytial virus, adenovirus infection, or sudden unexpected death in infancy [31-40]. Generally, CPT II deficiency has three clinical presentations: a lethal neonatal form, a severe infantile hepatocardiomuscular form, and a myopathic form (which is usually mild and can manifest from infancy to adulthood) [41]. While the former two are severe multisystemic diseases characterized by liver failure with hypoketotic hypoglycemia, cardiomyopathy, seizures, and early death, the latter is characterized by recurrent exerciseinduced muscle pain and weakness, sometimes associated with myoglobinuria, resembling our case [41]. The myopathic form of CPT II deficiency is the most common disorder of lipid metabolism affecting the skeletal muscle and is the most frequent cause of hereditary myoglobinuria, and males are more likely to be affected than females [41]. Accordingly, the thermolabile genetic phenotype of CPT II in the present case might have affected the occurrence of bimodal rhabdomyolysis, even during mild exercise like rehabilitation after depletion of energy in the muscle due to an initial attack of heat stroke [42]. Oda et al. also suggested that the thermolabile genetic phenotype of CPT II was a risk factor for severe heat stroke [43]. Like Reye syndrome, heat stoke induced by thermolabile genetic phenotype of CPT II might be classified as a fatty acid oxidation disorder in the future [44].

\section{Conclusions}

Physicians should pay special attention to the stress of rehabilitation exercises, which may cause collapsed muscles that are injured by severe heat stroke to repeatedly flare up.

\section{Abbreviations \\ AST: Aspartate aminotransferase; CHDF: Continuous hemodiafiltration; CPK: Creatinine phosphokinesis; PE: Plasma exchange}

\section{Acknowledgements \\ None. \\ Funding \\ This manuscript obtains financial support from the Ministry of Education, Culture, Sports, Science and Technology (MEXT)-Supported Program for the Strategic Research Foundation at Private Universities, 2015-2019 concerning [The constitution of total researching system for comprehensive disaster, medical management, corresponding to wide-scale disaster].}

\section{Authors' contributions}

$\mathrm{KO}, \mathrm{IT}, \mathrm{YM}, \mathrm{KJ}, \mathrm{KI}, \mathrm{HO}$, and MS provided medicine for the patient and edited the draft of the manuscript. HK and ET provided genetic analysis. TK and YY provided medicine for the patient and wrote the manuscript as a corresponding author. All authors read and approved the final manuscript.

\section{Competing interests}

The authors declare that they have no competing interests.

\section{Consent for publication}

Written informed consent was obtained from the patient for publication of this case report and any accompanying images.

\section{Ethics approval and consent to participate}

The study was approved by our institutional ethics committee (Juntendo Igakugufuzoku Shizuoka Byouin Rinrishinnsa linkai). There was no reference number.

\section{Author details}

${ }^{1}$ Department of Acute Critical Care Medicine, Shizuoka Hospital, Juntendo University, Tokyo, Japan. ${ }^{2} 1129$ Nagaoka, Izunokuni City, Shizuoka 410-2295,

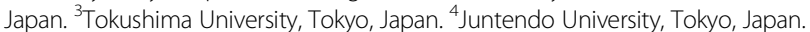




\section{References}

1. Trujillo MH, Fragachán GC. Rhabdomyolysis and acute kidney injury due to severe heat stroke. Case Rep Crit Care. 2011;2011:951719.

2. Carter 3rd R, Cheuvront SN, Williams JO, Kolka MA, Stephenson LA, Sawka MN, Amoroso PJ. Epidemiology of hospitalizations and deaths from heat illness in soldiers. Med Sci Sports Exerc. 2005;37:1338-44.

3. Glazer JL. Management of heatstroke and heat exhaustion. Am Fam Physician. 2005;71:2133-40.

4. Brown J, Mitchell S. A complicated case of exertional heat stroke in a military setting with persistent elevation of creatine phosphokinase. Mil Med. 1992;157:101-3.

5. Huerta-Alardín AL, Varon J, Marik PE. Bench-to-bedside review: rhabdomyolysis - an overview for clinicians. Crit Care. 2005;9:158-69.

6. Khan FY. Rhabdomyolysis: a review of the literature. Neth J Med. 2009:67:272-83.

7. Yanagawa $Y$, Kanawaku $Y$, Kanetake J. A case of lethal muscle contusion by assault. Open Access Emerg Med. 2012;4:1-3.

8. Sugawara K, Nakayama N, Mochida S. Acute liver failure in Japan: definition, classification, and prediction of the outcome. J Gastroenterol. 2012:47:849-61.

9. Asserraji M, Benameur I, Maoujoud O, El Kharras A, Hajbi H, Filali K. Late care in marathon runs leading to exertional heat stroke with multiple organ failure. Asian J Sports Med. 2014;5:136-8.

10. Raj VM, Alladin A, Pfeiffer B, Katsoufis C, Defreitas M, Edwards-Richards A Chandar J, Seeherunvong W, McLaughlin G, Zilleruelo G, Abitbol CL. Therapeutic plasma exchange in the treatment of exertional heat stroke and multiorgan failure. Pediatr Nephrol. 2013;28:971-4.

11. Horseman MA, Rather-Conally J, Saavedra C, Surani S. A case of severe heatstroke and review of pathophysiology, clinical presentation, and treatment. J Intensive Care Med. 2013;28:334-40.

12. Azzopardi N, Chetcuti S, Sant J, Pocock J. Acute liver impairment in a young, healthy athlete: hypoxic hepatitis and rhabdomyolysis following heat stroke. Case Rep Gastroenterol. 2012;6:563-8.

13. Muñiz AE. Ischemic electrocardiographic changes and elevated troponin from severe heatstroke in an adolescent. Pediatr Emerg Care. 2012;28:64-7.

14. Lin PY, Lin CC, Liu HC, Lee MD, Lee HC, Ho CS, Chiu NC, Peng CC, Huang FY, Tsai JD. Rasburicase improves hyperuricemia in patients with acute kidney injury secondary to rhabdomyolysis caused by ecstasy intoxication and exertional heat stroke. Pediatr Crit Care Med. 2011;12:e424-7.

15. Miura H, Yoshimoto H, Kitamura S, Hi Y. Fulminant hepatic failure accompanied by fatal rhabdomyolysis following exertional heatstroke. Clin J Gastroenterol. 2010;3:318-23.

16. Lee CW, Perng CL, Huang YS, Luo JC, Hung CL, Lin HC. Multiple organ failure caused by non-exertional heat stroke after bathing in a hot spring. J Chin Med Assoc. 2010;73:212-5.

17. Niu KC, Chang CK, Lin MT, Huang KF. A hyperbaric oxygen therapy approach to heat stroke with multiple organ dysfunction. Chin J Physiol. 2009;52:169-72.

18. Akieda K, Yamamoto R, Tamura K, Morita S, Amino M, Sakurai K, Otsuka H, Motojuku M, Inokuchi S. Successful treatment of a case with acute hepatic failure following hot bath immersion. Tokai J Exp Clin Med. 2008;33:65-9.

19. Fink E, Brandom BW, Torp KD. Heatstroke in the super-sized athlete Pediatr Emerg Care. 2006;22:510-3.

20. Broessner G, Beer R, Franz G, Lackner P, Engelhardt K, Brenneis C, Pfausler B, Schmutzhard E. Case report: severe heat stroke with multiple organ dysfunction-a novel intravascular treatment approach. Crit Care. 2005;9:R498-501

21. Wakino S, Hori S, Mimura T, Fujishima S, Hayashi K, Inamoto H, Saruta T, Aikawa N. Heat stroke with multiple organ failure treated with cold hemodialysis and cold continuous hemodiafiltration: a case report. Ther Apher Dial. 2005;9:423-8.

22. Takahashi K, Chin K, Ogawa K, Kasahara M, Sakaguchi T, Hasegawa S, Sumi K, Nakamura T, Tamaki A, Mishima M, Nakamura T, Tanaka K. Living donor liver transplantation with noninvasive ventilation for exertional heat stroke and severe rhabdomyolysis. Liver Transpl. 2005;11:570-2.

23. Pechlaner C, Kaneider NC, Djanani A, Sandhofer A, Schratzberger P, Patsch JR. Antithrombin and near-fatal exertional heat stroke. Acta Med Austriaca. 2002;29:107-11.

24. Wu B, Gong D, Ji D, Xu B, Liu Z. Clearance of myoglobin by high cutoff continuous veno-venous hemodialysis in a patient with rhabdomyolysis: a case report. Hemodial Int. 2015:19:135-40.
25. Mishra A, Dave N. Acute renal failure due to rhabdomyolysis following a seizure. J Fam Med Prim Care. 2013;2:86-7.

26. Suzuki T, Takagi M, Hirano M, lizuka T. A case of heat stroke with acute rena failure due to marked rhabdomyolysis. Chiryo. 1996;78:183-7. In Japanese.

27. Kuriyama M, Matsuno $F$, Ueno $H$, et al. A case of heat stroke with re-increase of value of creatinine phosphokinase. Kanto J Jpn Asso Acute Med. 1990;11:72-4. In Japanese.

28. Kajiwara H, Suzaki S, Matsuda S, et al. Usefulness of step up rehabilitation in recovery phase of heat stroke. Kanto J Jpn Asso Acute Med. 1993;14:288-90. In Japanese.

29. Nagao K, Uematsu K, Yazaki S, et al. Rhabdomyolysis in recovery phase of heat stroke. Jpn J Acute Med. 1985;9:1775-9. In Japanese.

30. Coco TJ, Klasner AE. Drug-induced rhabdomyolysis. Curr Opin Pediatr. 2004;16:206-10

31. Yamamoto T, Tanaka H, Emoto Y, Umehara T, Fukahori Y, Kuriu Y, Matoba R, Ikematsu K. Carnitine palmitoyltransferase 2 gene polymorphism is a genetic risk factor for sudden unexpected death in infancy. Brain Dev. 2014;36:479-83.

32. Sigauke E, Rakheja D, Kitson K, Bennett MJ. Carnitine palmitoyltransferase II deficiency: a clinical, biochemical, and molecular review. Lab Invest. 2003:83:1543-54

33. Kubota M, Chida J, Hoshino H, Ozawa H, Koide A, Kashii H, Koyama A, Mizuno Y, Hoshino A, Yamaguchi M, Yao D, Yao M, Kido H. Thermolabile CPT II variants and low blood ATP levels are closely related to severity of acute encephalopathy in Japanese children. Brain Dev. 2012;34:20-7.

34. Yao D, Mizuguchi H, Yamaguchi M, Yamada H, Chida J, Shikata K, Kido H. Thermal instability of compound variants of carnitine palmitoyltransferase ॥ and impaired mitochondrial fuel utilization in influenza-associated encephalopathy. Hum Mutat. 2008;29:718-27.

35. Chen Y, Mizuguchi H, Yao D, Ide M, Kuroda Y, Shigematsu Y, Yamaguchi S, Yamaguchi M, Kinoshita M, Kido H. Thermolabile phenotype of carnitine palmitoyltransferase II variations as a predisposing factor for influenzaassociated encephalopathy. FEBS Lett. 2005;579:2040-4.

36. Mak CM, Lam CW, Fong NC, Siu WK, Lee HC, Siu TS, Lai CK, Law CY, Tong SF, Poon WT, Lam DS, Ng HL, Yuen YP, Tam S, Que TL, Kwong NS, Chan AY. Fatal viral infection-associated encephalopathy in two Chinese boys: a genetically determined risk factor of thermolabile carnitine palmitoyltransferase II variants. J Hum Genet. 2011:56:617-21.

37. Kobayashi Y, Ishikawa N, Tsumura M, Fujii Y, Okada S, Shigematsu Y, Kobayashi M. Acute severe encephalopathy related to human herpesvirus-6 infection in a patient with carnitine palmitoyltransferase 2 deficiency carrying thermolabile variants. Brain Dev. 2013;35:449-53.

38. Hu J, Chen Z, Liu X, Chen Z, Xin D, Liu P. Association of CPT II gene with risk of acute encephalitis in Chinese children. Pediatr Infect Dis J. 2014;33:1077-82.

39. Yao D, Yao M, Yamaguchi M, Chida J, Kido H. Characterization of compound missense mutation and deletion of carnitine palmitoyltransferase II in a patient with adenovirus-associated encephalopathy. J Med Invest. 2011;58:210-8.

40. Yao M, Cai M, Yao D, Xu X, Yang R, Li Y, Zhang Y, Kido H, Yao D. Abbreviated half-lives and impaired fuel utilization in carnitine palmitoyltransferase II variant fibroblasts. PLoS One. 2015;10:e0119936.

41. Wieser T. Carnitine palmitoyltransferase II deficiency. In: Pagon RA, Adam MP, Ardinger HH, Wallace SE, Amemiya A, Bean LJH, Bird TD, Fong CT, Mefford HC, Smith RJH, Stephens K, editors. GeneReviews ${ }^{\oplus}$. Seattle: University of Washington; 2004. p. 1993-2016.

42. Topçu Y, Bayram E, Karaoğlu P, Yiş U, Bayram M, Kurul SH. Carnitine palmitoyl transferase II deficiency in an adolescent presenting with rhabdomyolysis and acute renal failure. Pediatr Emerg Care. 2014;30:343-4.

43. Oda J, Yukioka T, Kido Hm Azuma K, Ohta S, Yao M, Chida J. Thermolabile genetic polymorphism may be a serious risk factor for heat stroke. Jpn Asso Acute Med. 2011:22:350-1. In Japanese.

44. Tein I. Impact of fatty acid oxidation disorders in child neurology: from Reye syndrome to Pandora's box. Dev Med Child Neurol. 2015:57:304-6. 